S2 File

\title{
Lifestyle in the general practice
}

Welcome to this study and thank you for your participation.

This questionnaire is about lifestyle in general practice and will take about 10 minutes to fill out.

The target group of this questionnaire is general practitioners (GPs) in the Netherlands.

The aim of this study is to gain insight into how GPs relate to lifestyle. Every 25th

respondent who completes the questionnaire receives a gift voucher worth 25 euros. Your data will be processed anonymously. If you wish to contact the researcher to discuss this research or receive the results of this study, you can send an email to info@artsenleefstijl.nl.

\section{Permission}

By starting the questionnaire, you agree to participate in this study on a voluntary and anonymous basis, knowing that you can withdraw from this study and that your answers will be used in scientific research.

Yes I agree with this

No I do not agree with this 
In this questionnaire, lifestyle means the following: 'Lifestyle is a collective name for a person's behaviour with regard to nutrition, physical activity, sleep, stress, smoking and alcohol use.'

\section{Discussing lifestyle}

Discussing lifestyle means the following : "Giving active attention to lifestyle during a consultation, whereby the patient gains insight into his lifestyle behaviour."

Q2 'I think discussing lifestyle is...' Indicate the place that applies to you

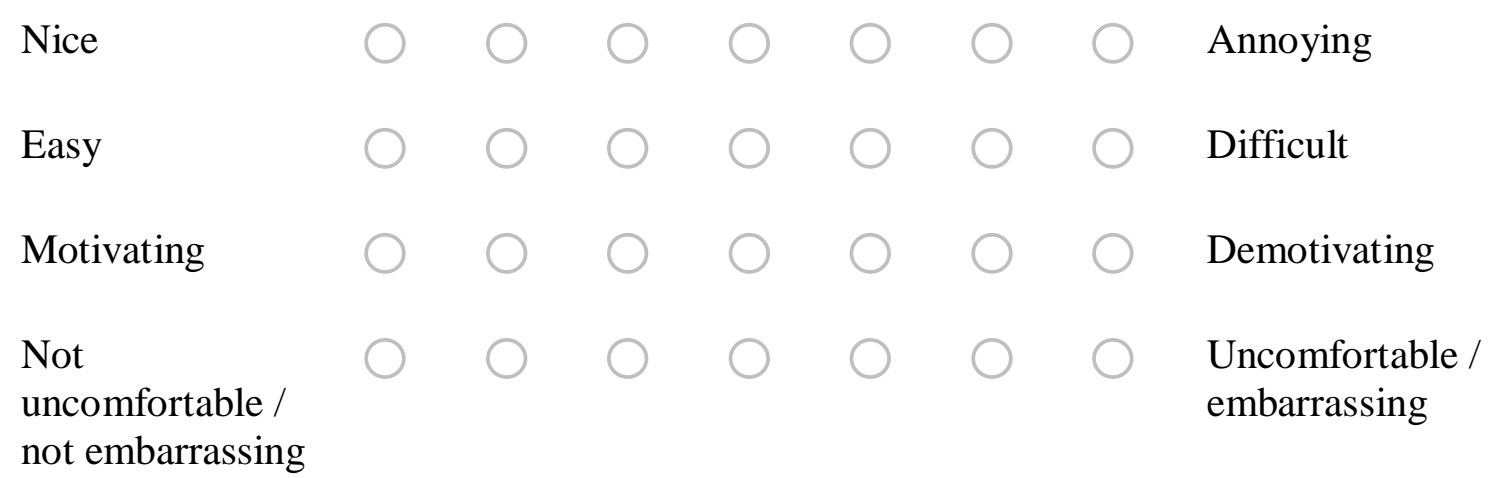

Q3 'I think discussing lifestyle is... ' Indicate the place that applies to you

$\begin{aligned} & \text { One of my } \\ & \text { tasks a GP }\end{aligned}$
$\begin{aligned} & \text { Impoful } \\ & \text { improve the } \\ & \text { health of } \\ & \text { my patients }\end{aligned}$

Q4 How often do you ask your patients...

Never Rarely Sometimes Very often Always

About their

lifestyle?

Whether they are motivated to change their lifestyle? 
Q5 How easy do you find it to discuss the following lifestyle habits?

\begin{tabular}{|c|c|c|c|c|c|}
\hline & Very easy & Easy & Neutral & Difficult & $\begin{array}{l}\text { Very } \\
\text { difficult }\end{array}$ \\
\hline Smoking & 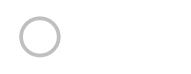 & $\bigcirc$ & $\cap$ & 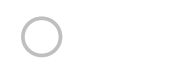 & $\bigcirc$ \\
\hline Alcohol use & & $\bigcirc$ & 0 & & C \\
\hline Nutrition & $\bigcirc$ & $\bigcirc$ & & & \\
\hline $\begin{array}{l}\text { Physical } \\
\text { activity }\end{array}$ & $\Omega$ & ( & $\Omega$ & & \\
\hline Sleep & $\Omega$ & $\bigcirc$ & 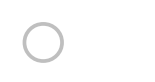 & 0 & C \\
\hline Stress & $\bigcirc$ & O & $\bigcirc$ & $\bigcirc$ & O \\
\hline
\end{tabular}

Q6 Give your opinion on each of the statements below

\begin{tabular}{|c|c|c|c|c|c|}
\hline & $\begin{array}{l}\text { Strongly } \\
\text { disagree }\end{array}$ & Disagree & Neutral & Agree & Totally agree \\
\hline $\begin{array}{l}\text { GPs should } \\
\text { discuss lifestyle }\end{array}$ & O & O & $\bigcirc$ & C & 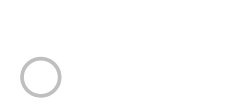 \\
\hline $\begin{array}{l}\text { I believe other } \\
\text { GPs discuss } \\
\text { lifestyle }\end{array}$ & 0 & $\mathrm{C}$ & O & $C$ & \\
\hline $\begin{array}{l}\text { Obelieve patients } \\
\text { expect me to } \\
\text { discuss lifestyle }\end{array}$ & ○ & 0 & 0 & 0 & ) \\
\hline
\end{tabular}

Q7 How often do you discuss the following factors that may (possibly) present a barrier to a healthy lifestyle for patients?
Never
Barely
Sometimes Often
Always

Stress

Temptations 
Lack of time

Lack of

knowledge

Lack of

motivation

Lack of

financial

resources

Lack of

confidence

Otherwise, namely

Q8 To what extent do you know the guideline daily amount of fruit and vegetables of the Voedingscentrum?

Not at all

Barely

To a reasonable degree

To a high degree

To a very high degree

Q9 Do you take a nutritional history at your patients?

Yes

No

Display this question:

If $Q^{9}=$ Yes

Q10 In case of which disease do you take a nutritional history? (You can tick multiple options)

Hypertension

Hypercholesterolemia 
Obesity / overweight

Diabetes

Intestinal complaints

Cancer

Heart and vascular diseases

Otherwise, namely

Q11 Do you discuss the fruit and vegetable consumption of your patients?

No

Yes, I ask to it if I think it is relevant

Yes, if the nutritional history shows that a patient is not eating enough fruit and vegetables

\section{Advising lifestyle}

Advising lifestyle means the following: 'Giving patients personal advice on their lifestyle, including providing information on health risks and health benefits to encourage behavioural change.'

Q12 Based on the assessment, how often do you advise your patients on the following lifestyle habits?

Never Rarely Sometimes Often Always

Smoking

Alcohol use

Nutrition

Physical

activity

Sleep

Stress 
Q13 Give your opinion on each of the statements below

$\begin{array}{clll}\text { Not at all Barely } & \begin{array}{l}\text { To a } \\ \text { reasonable } \\ \text { degree }\end{array} & \begin{array}{l}\text { To a high } \\ \text { degree }\end{array} & \begin{array}{l}\text { To a very } \\ \text { high degree }\end{array}\end{array}$

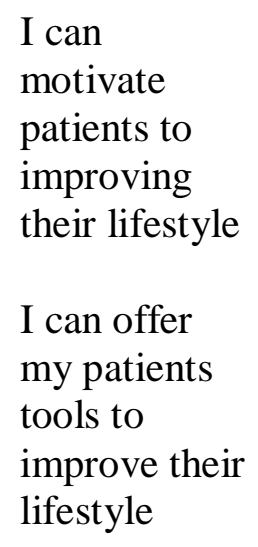

Q14 When you advise your patients, how often do you set concrete goals together to change the following lifestyle habits?

Never Barely Sometimes Often Always

Smoking

Alcohol use

Nutrition

Physical

activity

Sleep

Stress

Q15 How often do you advise your patients about eating fruits and vegetables?

Never

Barely

Sometimes

Often 
Very often

Q16 What daily amount of fruit and vegetables do you recommend to your patients? (vegetables in grams, fruit in pieces)

Vegetables

Fruit

Q17 What do you do if a patient has a too low intake of fruit and vegetables? "" I ... "" (You can check multiple options)

Ask the patient for the cause of this

$\square$ Mention the recommended amount of fruits and vegetables

Provide advice on how to increase fruit and vegetable consumption

Provide information material (e.g. leaflet)

Refer to a dietician

Refer to a nurse / practice assistant

Otherwise, namely

\section{Barriers, wishes and needs}

Q18 'I would like to discuss / advise lifestyle more often than I do now'

Yes

No

Display this question:

If $Q 18=$ Yes

Q19 'I discuss / advise lifestyle less often than I would like by ...'

Totally

Totally

disagree

agree 
My lack of

motivation

Lack of time

Lack of knowledge

Lack of confidence

Lack of financial

compensation

Lack of prove /

guideline

Lack of supporting

tools

Lack of overview of referring

possibilities

Patients who do not need this

The low education level of some patients

Fair to disrupt the relation with the patient

Unmotivated patients

Language / culture barrier in my patients

Other problems that affect patients 
The current

structure of our

health system

Display this question:

If $Q 18=$ Yes

Otherwise, namely

Display this question::

If $Q 18=$ Yes

Q20 What would motivate you most or help you to discuss / advise lifestyle more often? (Use at least 10 characters)

Q21 What would you need to be able to discuss fruits and vegetables more often during a consultation?

\begin{tabular}{|c|}
\hline $\begin{array}{l}\text { Totally } \\
\text { disagree }\end{array}$ \\
\hline
\end{tabular}

I do not have

this need

More

knowledge

about the

importance of

fruit and

vegetables

Scientific

evidence for the

effects of fruits

and vegetables

Success stories

of other GPs

Supporting tools 
NHG guidelines

about fruit and

vegetables

Cooperation

with, for

example, the

local

supermarket /

grocery

Otherwise, namely

Q22 Are you experiencing one or more factors that hinder the proper discussion / advice of fruit and vegetables?

Yes

No

Display this question:

If $Q 22=$ Yes

Q23 What factor(s) do you experience that form(s) a barrier for the proper discussion / advice of fruit and vegetables? (use at least 10 characters)

Q24 Which of the following options might be interesting for your practice to encourage your patients to eat fruits and vegetables? (You can check multiple options)

Discount coupons for fruit and vegetables for my patients, for example, at supermarkets / greengrocers

Free snack vegetables in the waiting or consultation room

Information about the importance of fruit and vegetables (leaflets, video's)

More standard offers on fruit and vegetables, for example in supermarkets

More nudges (provoking behaviour) aimed at fruit and vegetables in supermarkets (colours, images, shelf layout)

Better communication (information on fruit and vegetables, recipes, demonstrations) 
None of them

Otherwise, namely

\section{Referring and follow-up support}

Q25 How often do you refer your patients to other professionals to improve their lifestyle?

Never

Barely

Sometimes

Often

Always

Q26 When you refer your patients to improve their lifestyle, how often do you refer them to the following healthcare professionals?
Never
Barely
Sometimes
Often
Always

Physiotherapist

Dietician

Practice

assistant /

nurse

Registered

lifestyle coach

(BLCN)

Psychologist

Medical doctor

Q27 Is fruit and vegetable consumption a subject that is discussed in your coordination with dieticians and practice assistants?

Yes

No 
Q28 Are you familiar with the fact that as of 1 January 2019 you can refer patients to combined lifestyle interventions (GLI's)?

Yes

No

Q29 Do you refer to combined lifestyle interventions (GLI's)?

Yes

No

Q30 If I don't refer patients to combined lifestyle interventions (GLI's) / or less than I would like, this is because of...

Totally
knowledge
about GLI's
Lack of trust
in GLI's
Lack of time
Lack of
motivation
Lack of
GLI's nearby
Insecurity
about
financial
compensation
in the future
Preference for
referring to
familiar
professionals
within or


outside my

practice

Otherwise, namely

Q31 When you give your patients lifestyle advice, how often do you provide follow-up support to them, for example, follow-up appointment, follow-up call, and/or medication reduction?

Never

Barely

Sometimes

Often

Always

Q32 When your patients undergo a lifestyle intervention, how often do you taper off medication?

Never

Barely

Sometimes

Often

Always

Q33 How do you rate your own lifestyle? 
10

General questions (The questionnaire now takes less than half a minute)

Q34 What is your gender?

Female

Male

Q35 What is your age?

$\overline{\text { Q36 How many working days do you work on average as a general practitioner? }}$

Q37 What is the postcode of your general practice? (only the numbers)

Q38 Are you working in a...

Solo practice

Solo practice in health centre

Independent duo practice

Duo practice in health centre

Independent group practice

Group practice in health centre

Q39 Are you familiar with Vereniging Arts \& Leefstijl? 
No I do not know it

Yes I know it, but no member and have not been to a training

Yes I know it, member, but not have been to a training

Yes I know it, member and have been to a training

This is the end of the questionnaire. If you want to win the gift voucher of 25 euros, you can leave your email address below. 